\title{
Dr John Burton (1710-1771) of York and his obstetric treatise
}

\author{
P M Dunn
}

John Burton was born in Colchester on 9 June 1710. His father, John, was a London merchant and his mother, Margaret, the daughter of the Rev J Leake. After schooling at Merchant Taylor's, he graduated MB at St John's College, Cambridge in 1733. He then pursued his training abroad in Leyden, Paris, and also at Rheims where he obtained the degree of MD. Returning to England, he married Mary Henson in York Minster and settled in Wakefield. In 1738 he moved to York where in 1740 , he was one of the prime movers in founding the York Hospital, becoming its first physician.

While Burton's reputation as a doctor, manmidwife, and public spirited person was high, he was a peppery sort of individual, conceited, hypercritical of the work of others, paranoid, and extremely sensitive to criticism. While he expressed admiration for Mauriceau, Deventer, La Motte, and Gifford, all other authors on midwifery were dismissed as worthless. Of his colleagues he commented: ". . the frequency of the almost innumerable evils which daily befel the woman and their infants during labour, by the ignorance and mismanagement of the female-midwives . . . many of the male practitioners are no less excusable than the women ... the weaker and more ignorant these men are, the more freely they use instruments, and that too, very often, to the destruction of the mother as well as the child ..." In particular, he launched a vitriolic attack on William Smellie a year after the publication of the first volume of the latter's masterpiece in 1752. Perhaps it was for this reason that Sterne satirised Burton as Dr Slop in Tristram Shandy.

During the 1975 Jacobite rebellion, it is said that Burton joined the army of the young Pretender as it came south. His own story, though, given later, was that he had been held a prisoner for those three months!

Burton's most important contribution to medicine was his essay on midwifery. ${ }^{1}$ It was published in 1751, probably to pre-empt that of Smellie; for he wrote: "I was informed, that another person was about to publish my improvement with some other works of his own; this put me upon the thoughts of publishing them myself ..."

Although Burton's treatise misses the more practical approach of Smellie, it is still a fine essay that can be read with enjoyment. Among his many contributions was the suggestion that puerperal fever was a contagious disease and that the maternal and fetal circulations were quite separate. He expressed his own philosophy on medical investigations as follows: "Facts justly represented are real permanent things; but reasons or conclusions drawn from them frequently alter with the times ... as nature discloses herself in an obscure manner, we must strictly observe her operations, by which we shall see the facts; and then a thorough knowledge of philosophy and anatomy will enable us, by such guides, to penetrate into her secret principles... A knowledge therefore, derived from physical experiments, nature and the operations of medicines, founded upon the causes of diseases, the observations of their symptoms, and the laws of the animal oeconomy, is what constitutes the true theory; which is no more than practice reduced to rules.”

\section{On the nourishment of the fetus ${ }^{1}$}

" . . it is evident, that the circulation is not carried on from the mother to the foetus, nor from the foetus to the mother, by continued canals, but by the extremities of the umbilical vein taking up liquors by absorbtion, in the same way as the lacteal vessels do in the guts; and the umbilical arteries pour their liquors into the large cavities of the sinuses, or other cavities analogous to them: for the uterine sinuses seem to be to the foetus, what the intestines are to an adult: the uterine blood, poured into the sinuses, being analogous to the recent ingesta of food and drink ... the grosser parts of the blood in the sinuses are carried back by the veins of the womb, as the excrements of the guts are discharged at the anus. By this means the foetus is solely nourished, and thus the circulation and communication of the humours betwixt mother and foetus are performed ..."

\section{On the liquor amnii ${ }^{1}$}

"The foetus in utero swims in a liquor, which is contained in a bag called the amnios . . . This liquor amnii is in larger proportional quantity, the younger the foetus is; which seems to be very providential, because, the younger the foetus is, the more danger there 
is of its being hurt by an outward pressure; and at the same time it extends the bag, so as to fill up every space in the womb, as it alters in shape ... From what has been said, it is evident, first, that a foetus is capable of receiving its whole nourishment by the umbilical vein alone, whereas none can subsist without the umbilical vessels. Secondly, that the liquor amnii is ill calculated, in its natural state, for the food of a foetus; and, in morbid cases, becomes altogether unfit; and it is highly improbable, that a creature should furnish its food out of its own body; which must be the case, if the foetus should feed on this liquor."

\section{On the posture of the fetus ${ }^{1}$}

"That the posture above described arises from the natural contraction of the muscles, while the foetus is in a sleeping state, is farther evinced, by observing how much children sleep after they are born, and how the members naturally go into near the same posture when people fall asleep; and a newborn child, laid naked upon a table, will immediately draws its limbs into the same posture as they were in the womb..." (fig 1).

\section{On touching and the left lateral delivery position $^{1}$}

"Touching, as it is commonly called, is the introduction of a finger up the vagina, as far as the os uteri, to find the condition it is in, the state of the membranes and what part of the child presents. How the patient is to be placed while the operator is touching her, is not very material; but how she ought to be placed during her delivery, is a point not altogether determined, some being for doing it standing; others, sitting on the stool, or the knee of some of the females in waiting; whilst others are for delivering the women lying in

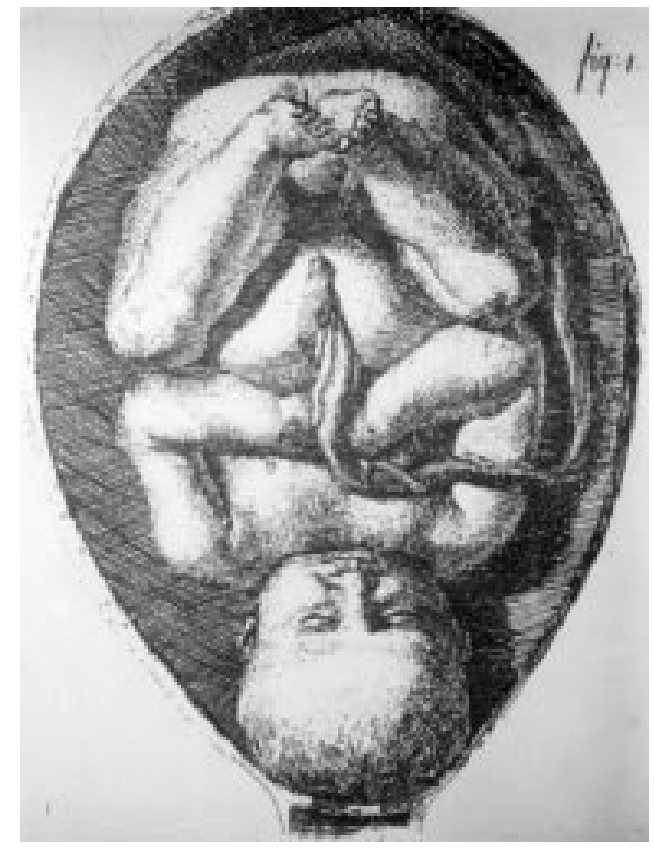

Figure 1 A fetus in utero from Burton's essay, 1751. or upon the bed; and these also differ in the opinions, whether the women should lie on her back, or on one side. I shall offer my reasons for the position, which I have found by experience to be the best, safest, and easiest for the patient, as well as most convenient for the operator: but I must premise to the reader, that I am here speaking of natural births only ... Now it is evident if the patient either sit on the stool, or on the knee of another woman, if the os coccygis will yield, it must be pressed inwards; which would in course straiten the passage, and therby delay the birth of the child ... The woman, therefore, should lie on one side, with her face and breast inclining forwards, and her knees as near her breast as conveniently she can, having a small warm pillow betwixt them; and the pudenda must be near the edge of the bed, with her back in an oblique direction from that to the middle of the bed; and a person should sit close to the bed-side, for the patient to place her feet against. The operator should be nigh the patient, either sitting or kneeling close to the bed-side ... with a sheet or cloths before him, having his hand under the cloths well greased with oil ..."

\section{On caesarean delivery ${ }^{1}$}

"As the circulation of the blood, in both mother and child, depends upon their own hearts and vessels, the one can live, although the other die; as has been proved from performing the caesarean operation, after the mother has been dead some time, and living children have been taken out ... These facts are sufficient to support my argument for always opening a pregnant woman, when she dies in the two or three last months of her time ... The second case, where the caesarean operation is necessary is, when both mother and foetus are alive, but no possibility of delivery in the natural way, from some of the causes above mentioned, but especially from the bad conformation of the parts of the mother, which will always prevent the operator's introducing his hand, in order to take hold of the child's feet, or to extract it, even by piece-meal. To abandon a poor woman to certain death, in such circumstances . . . is a great piece of inhumanity ... the objection made by some, that when this operation is performed, the patient must bleed to death; because it is evident this haemorrhage has nothing so terrifying in it, as they, who have performed this operation, tell us it is not very considerable; for this incision is made in the bottom of the womb, which, by reason of the muscular fibres, discovered by Malpighius and Ruysch, is extremely elastic; consequently, these fibres, like bandages in re-uniting the lips of the wound, must, upon their contraction, speedily stop the haemorrhage, especially as the womb is empty at the time ..." Burton was also a good classical scholar who obtained eminence as an antiquarian. In 1758 he published the Monasticou Eboraceuse and 
ecclesiastical history of Yorkshire, an important contribution to the archaeology of the county; further tracts on Yorkshire antiquities followed in 1768-1771. He died on January 19th, 1771, and was buried in Holy Trinity Church, Mick- legate. His wife, Mary, was buried at his side a few months later.

1 Burton J. An essay towards a complete new system of midwifery, 